\title{
Dynamic Assessment and the Impact on English Language Learners' Reading Comprehension Performance
}

\section{JILA NAEINI}

Department of English Language, Science and Research Branch, Islamic Azad University Tehran, Iran

EMILY DUVALL

University of Idaho, Coeur d'Alene, US

\section{Bio Data:}

Jila Naeini is a PhD candidate at Islamic Azad University, Science and Research Campus in Iran and she is the ELT faculty member at AKIAU. She has been lecturing at universities in Iran for over 6 years. She has special interest in "assessment."

Emily Duvall has a PhD from Pennsylvania State University and is currently at the University of Idaho where she is Assistant Professor of Curriculum \& Instruction, Assistant Professor of Neuroscience and Director, Northwest Inland Writing Project.

\begin{abstract}
This paper reports the results of a research project aimed at studying improvements in English Language Training (ELT) university students' reading comprehension performance by applying the mediations of a dynamic assessment approach to instruction and assessment. In contrast to static assessments, in which correct responses are indicative only of the learners' current ability at a specific moment in time, dynamic assessment concentrates on the learner's errors which are studied in terms of the individual's ongoing development and learning using mediations to promote growth. Lev Vygotsky (1978) is considered the originator of the theoretical framework upon which dynamic assessment is based; it emphasizes the interdependence of learning that leads development and thus the interlocking of instruction and development. In this mixed methods study, dynamic assessment procedures were conducted with 10 ELT university students. Participants took part in a pretest-mediationposttest design study. The devised pre and posttests had high reliability estimates. The mediation phase included three intervention sessions, each focused on a particular reading comprehension sub skill. The descriptive and analytic analyses of the results reveal dramatic,
\end{abstract}


measurable progress in participants' reading comprehension performance.

Keywords: assessment, dynamic assessment, alternative assessment, static assessment, English language learners

\section{Introduction}

Although language testing is one of the inseparable components of instructional language programs, the high stakes nature of the tests administered at schools and most educational settings have been criticized as responsible for narrowing the school curriculum since they direct teachers to focus only on the content included in the exams (Shepard, 2000). High stake tests have also been criticized for affecting the methodology that teachers apply in classrooms; according to Gipps (1994), high stakes tests affect the scope and types of instructional materials that teacher use in classes. In addition, student learning in high stakes contexts is superficial (Crooks, 1988) and students are said to be passive recipients in high stakes contexts, their needs generally ignored (Broadfoot, 2005) as they 'bank' the contents for future withdrawal on demand (Freire, 1970). High-stakes examinations also affect the methodology that teachers use in the classroom and direct teachers to focus only on those subjects and skills that are included in the examinations. Such tests are said to dominate and distort the whole curriculum (Kirkland, 1971).

Moreover, teacher made tests tend to draw attention toward grading rather than promote learning (Black, 1993; Crooks, 1988). Black and Williams (1998) argue that the competition created by these tests can lead to lack of motivation and loss of students' self-confidence. In fact, promotion of learning, the fundamental goal of education, is ignored begging the question: What is the role of education? Surely students don't attend educational settings simply for assessment purposes!

Alternative assessments, on the other hand, may be more useful and informative compared to an indifferent test score. Alternative assessments increase individual's awareness of their own learning dispositions and encourage them to take responsibility for their own learning (Crick, \& Yu, 2008). Moreover, alternative assessments are much easier to interpret given the fluid context of the classroom, offering the teacher and student perspectives that are both summative and formative in nature. Not surprisingly, alternative assessment is closely connected to sociocultural theory (Dysthe, 2011) in that such assessments are grounded in the social and the cultural landscape of the teaching and learning activity (Gipps, 1994, 1999).

One form of alternative assessment that has emerged from sociocultural theory is dynamic assessment (DA), rooted in Vygotsky's zone of proximal development (ZPD). It is an approach which offers a diagnostic understanding of where the learner is at while simultaneously promoting development by offering the learner specific mediations or very small 'hints' during the assessment procedure, assisting the learner to move beyond or overcome, impediments to problem solving (Vygotsky, 1978; Lantolf \& Poehner, 2008). The current study seeks to apply DA as a complement to existing static testing and as a tool to foster learning. The significance 
of the study is with regard to the effects of DA on the learner as well as the design and its implementation process.

More specifically, this pilot study aims to examine the impact of mediation on ELT university students' reading comprehension performance. The impetus for choosing reading comprehension strategy use in this study comes from what Grab (2009) suggests are the higher-order cognitive processes with which the readers are engaged. Grab (2009, p. 51) points out that strategy use during reading, and its impact vis-à-vis effective reading comprehension, must be directed by the executive control mechanism. He stresses that in an assessment for learning the intention is to improve reading abilities and the goal should be to provide immediate feedback, engaging students in more effective reading performance. Hence, the carefully designed mediations of a dynamic may be especially efficacious in advancing reading comprehension success.

\section{Applying Assessment to Assist Learning}

The focus in educational assessment reform has begun to hone in on the pragmatic, on activities which are "meaningful, contextual and purposeful" (Wyatt-Smith, 2006); yet the struggle continues to be on ways to demonstrate what a student knows and what he or she can achieve (Wyatt-Smith \& Gunn, 2009). In other words, there is a gap or distance between what the student is able to demonstrate currently, without assistance (what he or she may be said to know), and the desired goal. Vygotsky calls this distance the zone of proximal development. The zone of proximal development (ZPD) is at the heart of sociocultural perspectives and defines the dialogic nature of teaching and learning processes (Nassaji \& Cumming, 2000). According to Lantolf \& Thorne (2006) sociocultural theory (SCT) is most compatible with theories of language in that they are focused on communication, cognition and meaning, merging with a theory of mediated mental acts that lead development. These acts occur when the learner and the "more knowledgeable other" are engaged in moving the learner forward in his or her problem solving (Vygotsky, 1978). Here the more knowledgeable other, often the teacher, regulates his or her engagement with the learner, paying careful attention to the "leading edge" of the ZPD and offering only the assistance or mediation needed (Vygotsky, 1978).

In SCT, it is through the engagement in activities mediated by others and/ or by cultural objects that the individual develops higher forms of consciousness (Vygotsky, 1978). This engagement with the social and cultural objects emphasizes the role of social interaction in the development of children's thinking, suggests Wertsch (1979) and he argues that adults also require external forms of assistance. Wertsch (1985) illustrates this by noting that if an adult is asked to multiply two sets of high numbers, he / she must rely on paper and pencil to complete the arithmetic operation, thus employing cultural objects/ tools to mediate or assist in the activity. As Poehner (2008, p.41) sums up, a sociocultural perspective posits a mediated relationship between humans and the world. Therefore, if we take seriously the concept of a ZPD, the implication is that assistance should be given to the learner during assessment in order to see what they are truly capable of. In this regard, Vygotsky (1978) observed that it is what individuals are able to do in cooperation with others that indicates their future independent performance. 
Understanding what a student has learned is inferred through the evidence provided by observable actions such as writing and speaking and, thus, assessment should help to interpret the observed behavior. Griffin (2009) argues that teachers can study the data they collect from students and generalize, spotting where to initiate intervention. This data provides the foundation or basis for developmental learning. Furthermore, there is evidence from classrooms that, as Freire (1970) submits, students' understanding is not directly related to what they have been told or what they have read. Indeed, Freire argues against the model that positions the student as merely a vault for housing knowledge propositions, with the teacher's role as the one who fills the student as receptacle by making 'deposits' of information. He stresses that this banking concept of education transforms students into mere receiving objects rather than engaging them in dialogical activity. To that end, it also positions the teacher as the bestowing object. Freire feels that for the learner to move from object to subject, he or she needed to be involved in dialogical action with the teacher.

This brings us back to the key feature of Vygotsky's ZPD and its role in human development. The individual's development (the student) may be assisted by other members of the culture (the teachers) in face-to-face interaction (dialogue). Therefore, as Wells (2000) puts it, the application of Vygotskian theory to education calls for an approach to learning and teaching that is both exploratory and collaborative. That is, truly dialogical and dialectical in nature where the ends cannot be fully predetermined. This calls for the reconceptualization of curriculum whereby the educational activities will require more participation on the part of the students, encouraging them to go beyond themselves in order to press forward towards desired goals (Vygotsky, 1978).

Indeed, efforts are being made to envision alternative forms of education that will still meet requirements. These changes necessarily start within activity systems, the educational settings, and within which the participants need to be encouraged to become agents of change (Wells, 2000, p. 57). Thus, the urgent need is for dialogical and dialectical approaches to materialize in classrooms and schools, approaches in which students have significant roles not only in their own learning but also in the assessment procedures.

In this regard, in order for assessment to assist the process of learning, it should be instructionally supportive. Consequently, to accomplish this goal we have to make assessment more informative and we have to change the social meaning of evaluation (Shepard, 2000). In order to use assessment seriously to improve learning, Shepard (2000) suggests that the pervasive negative effects of tests should be recognized. Teachers need to find a way to protect their own developing understandings of constructivist assessment practices from the rampant test driven curricula. Shepard (2000) suggests, for example, that students can be encouraged to keep parallel sets of notes, one set for the 'real' knowledge and one for the knowledge they would need for the test. Shepard also includes dynamic assessment as an effective strategy that can be applied in order to change current cultural practices vis-à-vis learning, teaching, and assessment. 


\section{Distinguishing Characteristics of Dynamic Assessment}

Current and traditional approaches to curricula and assessment of learners' abilities have been the subject of strong criticism, criticisms that draw on the nature of the relationship between instruction and assessment. Traditional assessment practices have come under attack for both their predictive and prescriptive features (Campione, 1989).

Dynamic assessment (DA), grounded in Vygotsky's notion of the ZPD, focuses on what a learner is able to do with the assistance of a more knowledgeable another and the type and amount of mediation needed for a learner to be able to do a task in DA indicates the learner's learning potential. That is, the learner is able to overcome performance problems by working through his or her independent limitations as they engage and collaborate with the teacher who offers just the mediation(s) needed to assist the learner in moving themselves forward in the given activity. Thus, assessment and instructional activities are brought together in DA so that learner development is fostered. The significance of applying DA over non dynamic approach is shown in table (1).

In reviewing these characteristics, it is clear that in the design of assessment it is not only the differences in what is deemed of value and to whom that should be of note, but also the consequences of the assessment to the learner, "beg[ging] the question of who and what counts when it comes to accountability, but also who gets to benefit and how much" (Duvall, 2007). In DA the interests of the learner during the assessment are paramount whereas it could be argued that the interests of the learner during the assessment in non-DA activities are of little consequence. Indeed, of what benefit to the learner is the process of a non-DA assessment. In DA, every moment counts. Instruction is not suspended for assessment, but is the continuity thereof.

Haywood's words on DA may be more than enough justification for applying DA as an alternative assessment. Haywood (1992b, cited in Haywood \& Lidz, 2007) suggests that dynamic assessment is a subset of the more generic concept of interactive assessment (Kozulin, \& Garb, 2001; Jönsson, Mattheos, Svingby, \& Attström, 2007).

He further suggests DA as an interactive approach to psycho-educational assessment and explains that in DA the examiner enters an active relationship with a subject and does more than give instructions, pose questions, and record responses. He adds that the word "dynamic" in DA indicates those approaches in which the interaction is richer with the purpose of actual teaching. The interaction in DA, according to Haywood, is conscious, purposeful, and deliberate in order to produce change in the subject. In other words, consistent with a Vygotskian understanding of teaching and learning, the collaborative engagement of the "normal learning situation" is "a socially meaningful cooperative activity" whereby "new psychological functions... originate on this interpersonal plane and only later are internalized and transformed to become the [learner's] inner psychological processes" (Kozulin, 2005, p.354). Hence the fundamental nature of a lively and interactive assessment such as DA is what promotes change in the learner for learning does not occur in the isolation of a vacuum or during a static test. 


\section{Which Model of Dynamic Assessment?}

There are several approaches to dynamic psycho-educational assessment. Models generally differ in how they approach mediation (Poehner, 2008; Thouësny 2010). However, there are two general approaches to dynamic assessment: Interventionist and interactionist (Lantolf \& Poehner, 2008).

Feuerstein's interactionist model: Feuerstein fully integrates assessment and instruction so that the one doesn't exist apart from the other (Poehner, 2008). According to Feuerstein, human cognitive abilities are not fixed and can be modified or developed through interventions, thus, prevailing assumptions about normal distributions of intelligence and traditional psychometric models are challenged (Feuerstein \& Feuerstein, 2001). One of the concerns in such assessments is the issue of cultural differences, which Feuerstein also addresses (Lidz, 1983). In point of fact, in Feuerstein's Mediated Learning Experience (MLE) model, the stimulus-response model is altered so that the child is interacting with a more competent peer who helps the child in any way by selecting, changing, amplifying, and interpreting the objects with the child through mediations (Koulin, \& Pressisen, 1995).

Feuerstein et al. (1988, cited in Poehner, 2008, p. 57) outline 11 attributes of the MLE that differentiate the mediations of the MLE from other types of mediations. The MLE approach to mediation forms the theoretical framework for the Learning Potential Assessment Devise (LPAD) devised by Feuerstein and his colleagues (Poehner, 2008, p.60)). This is a battery of 15 instruments that can be dynamically administered to the learner bringing into being the learner's ZPD in which MLE can occur (Grigorenko, \& Sternberg, 1998).

In addition, Instrumental Enrichment (IE) programs (Poehner, 2008) were developed in order to provide the learner with an intensive mediational learning experience to remediate cognitive deficiencies stemming from psychological tool deprivation (International Center for the Enhancement of Learning Potential, 2011). Feuerstein et al. (1988, cited in Poehner, 2008) also emphasize that IE is different from other instructional programs in that the emphasis in IE is on providing the student with the opportunity to be able to learn how to acquire more information. IE tries to make the student more efficient in acquiring new skills and to finding adaptive ways to solve problems (Feuerstein et al., 1988, pp. 213-227).

Brown's interventionist model: Brown's Graduated Prompt (GP) model is grounded on the number of prompts needed to elicit a desired response. The learner's learning potential which is defined as a gain score (from the pretest to the posttest) is estimated by the number of prompts needed to get the goal and the level of transfer of learning to other tasks (Gutierrez, 2000).

Brown's GP is different from Feuerstein's MLE in that the mediation in Brown's GP model of DA is arranged from most implicit to most explicit and culminates with a correct answer (Poehner, 2008). The tests are also administered in an almost standardized manner and the examiner gradually provides the child with prompts if the child is not able to complete the task.

Grigorenko \& Sternberg's cake and sandwich formats: Two other forms of DA administration include the cake format and the sandwich format (Grigorenko \& Sternberg, 2002). The former is more integrated, offering mediation throughout the administration of the assessment, whereas the latter has a form similar to traditional 
assessments (Poehner, 2008), the pretest-intervention-posttest format. This is also the more widespread dynamic assessment format.

Generally speaking, specific DA models vary in individualizing the mediation during assessment procedure. During the graduated-prompt approach, the test is presented in a relatively standardized manner as in traditional tests (Brown \& Ferrara, 1984). Once the child is unable to complete a task, the examiner gradually provides clues or prompts and assesses how much and what type of information is required before the child is able to perform the task. These prompts are predetermined according to a careful analysis of the requirements of the task. Once the child completes the task successfully, a different version of the task is presented to determine whether the child can transfer any of the learning to the new task. Bryant, Brown and Campione (1983, cited in Poehner, 2008) found the graduated-prompt method to be effective in predicting children's ability to improve on tasks. Although the graduated-prompt approach has been used widely (Brown \& Ferrara, 1984; Campione \& Brown, 1987), it has been criticized for providing graduated prompts which are pre-determined, and as a result may not be sensitive to the needs of certain children who might be considered to have been subject to cognitive impoverishment (Missiuna \& Samuels, 1988).

The present study attempts to assist the EFL university student's reading comprehension performance by applying mediations in a DA procedure. Therefore the following research questions are addressed:

- Can mediation in DA influence EFL university students' reading comprehension performance?

- How might mediation in DA improve the EFL university students' reading comprehension performance?

\section{Current Study}

In order to answer the research questions, a mixed method approach was employed and qualitative and quantitative data gathered through single subject experiment, structured interview and an interventionist mediation program. According to Dornyei (2007), a mixed method approach can offer additional benefits for understanding the phenomenon in question. In terms of qualitative research in particular, Baxter and Jack (2008) point out that a qualitative case study methodology provides tools for researchers to study complex phenomena within their contexts. They emphasize that when the approach is applied correctly, it becomes a valuable method for science research to develop theory, evaluate programs, and develop interventions. Accordingly, issues of validity and reliability of the current study will be considered through this lens, particularly in regard to the data collected through the structured interview and the dialogue gathered during the mediation program.

The quantitative aspect of the study incorporates data collected through the administration of a pretest and a posttest. Specifically, the focus of the study looks to reveal variability and change in participants' reading comprehension performance as it is manifest in the results of the test questions and generally across the tests with mediations considered the independent variables and tests the dependent variables. This research study is modeled on what Best (2006, p. 224) referred to as A-B-A 
single subject design. This design is comprised of A (The baseline or the pretest), B (mediation program), and A (posttest).

\section{Participants}

A nonprobability sample design (Best, 2006) was used to select the participant population which resulted in 8 females and 2 males in the sample. Participants were selected from a pool of 19 undergraduate students in the Teaching English as a Foreign Language (TEFL) program and who were enrolled in a reading comprehension course at the Islamic Azad University, Aliabad branch. Selection was based on students' proficiency levels as assessed using the Preliminary English Test (PET). After the administration of the PET, those whose scores were 1 Standard Deviation (SD) above and $1 \mathrm{SD}$ below the mean score of the test were selected as participants in the study.

\section{Data Collection Process}

\section{Structured Interview}

In order to explore the participants' feelings and their understanding of reading, each student was individually interviewed using questions generated by the researchers. The interactions and dialogues between the students and the researchers were audiotaped for further analysis, also being used in the design of the mediation. Questions pertained to the students' understandings of reading and their awareness of the reading process is included the following:

1. How do you start a reading task? What are the things you do?

2. Do you think you are a good reader in comprehending a text?

3. What strengths and weaknesses do you see in yourself?

\section{Pre Test}

A static reading comprehension test (pretest) was administered to all participants at the outset of the study. The test included four passages taken from Philips (1996) and Baudoin (1977) and each passage was followed by some reading comprehension multiple choice questions. The entire pretest included 29 questions (4 questions on main idea, 6 questions pertaining to inference, 13questions on word meaning, and 6 questions on the details of the passages). The reliability and validity of the tests (pre and post) were estimated applying statistical analyses. In order to make sure that the tests (pre and post) were parallel, they were piloted with a sample of 25 students. The t-test was conducted and the results indicated that the tests were parallel.

The students' papers were collected after the administration of the pretest and the results were used to design the mediations. Table 2 shows the results and the students' performance on the pretest and posttest.

\section{Mediation}

The mediation program was aimed at supporting students in their development of conceptual understandings of reading that would assist them in using the strategies more appropriately. The results of the pretest indicated that most participants had difficulty finding the main idea of a passage, discovering the meaning of unknown words, and determining what might be implied in the passages. This information in 
tandem with the data gathered during the structured interviews provided the foundation for designing the mediations.

The mediation program provided participants with three sessions, approximately 30 minutes each, in a one-on-one format. Each session was focused on a specific sub skill and, while the sessions were primarily in English, the students' native language was also used to ensure comprehension. In other words, the students were told to feel free to communicate in their own language during the interactions.

The sessions were held in a large room in a quiet part of the university and were audiotaped. In addition, sessions were scheduled to suit the students. All students were aware that their participation was voluntary and that the mediation program was separate from their course grade. It is worth noting, however, that the students found the program very useful with regard to their reading comprehension course.

\section{Post Test}

After the three sessions of the mediation program, the participants were given a static posttest. The posttest included four passages with 29 multiple choice questions. The results are shown in table 2.

The students' reading comprehension improvement was then traced across the mediation sessions.

\section{Results and Discussion}

The mediation sessions were designed in such a way so as to manifest the participants' emerging conceptual understanding of reading comprehension strategies and their control over the application of the strategies in answering the comprehension questions through mediations in DA. As a result, the analysis of mediations and interactions between the student and the teacher (the researcher) is essential and useful in realizing the effects of dynamic assessment on the learners' performances in reading comprehension tests and realizing the changes that occur in the learners' performances in reading comprehension tests.

The DA procedure applied in the current study was structured according to what Grigorenko, \& Sternberg (2002) describe as the sandwich format in which the mediation phase is sandwiched between the pretest and the posttest. They note that the performance on the pretest and posttest is compared in order to determine how much improvement has been made as a result of the mediation. However, the current research sandwich design differs in that the mediation, which is in one-onone format, does not tend to be the same for everyone. As Duvall (2008) puts it, regardless of whether the mediation is interventionist, interactionist, or both, the responsibility is always on the ability of the examiner (the teacher) to develop a collaborative engagement with the learner so as to co-construct the learner's ZPD and frame the instruction in the subject-specific domain in that precise place of growth within the ZPD.

The mediation program began as the first session after the administration of the pretest. The pretest questions were sorted into three general categories (or sub skills) and each intervention or mediation session was focused on one of these so 
that students attended three intervention sessions with mediations that had been designed based on their performance on the pretest as well as data collected during the structured interview. Although the intervention sessions were preplanned by the researchers, the mediation program was not the same for all participants but was dependent on their individual needs.

\section{Lens Up Close: Examples of Mediation Sessions and What They Reveal}

The following transcriptions of excerpts from dialogues between students and researchers during the intervention sessions demonstrate some of the mediating prompts and the impact of the mediations. Below we see from the dialogues between the researcher (the mediator) and the student S1, that the learner was guided to find the best response through different prompts which included a lesson on using what the researcher notes as transitions, terms or phrases which link a main point with additional details.

Intervention session (1) with the researcher (R) and student 1 (S1): (The words in the students' native language have been italicized)

1. R: What is the answer to question 1 ? What is the main idea of the passage 1 ?

(S1 starts to read the passage)

2. S1: Is it (a)....... rules of etiquette?

3. R: Why did you choose (a)? Because it is at the beginning of the paragraph..?

4. S1: No

5. R: What does "etiquette" mean?

6. S1: price ....something .....barchasb (label)

7. R: No ....No. in this sentence it doesn't mean label (barchasb)

8. R: It...it is something about behavior.... a set of rules to be polite

9. S1: I didn't know

10. R: Sometimes, there are some strategies to help us to find the main idea, e.g 11. R: transitions help

12. S1: Transitions...?

13. R: words like "because" to show the reason, "but", they convey meaning

(S1 starts to read it again )

14. S1: yes ...here............in other words?

15. S1: The answer ..........is " $b$ "?

16. R: Is it giving you how to......

17. S1: No...no...

18. R: The writer is comparing........Which places mentioned?

19. S1: Coffee shop and....

20. R: two settings...

21. S1: Rustic and.....

22. R: Ye. So what is the purpose ....?

(looking at the other items)

23. S1: Variable yani (means)........?

24. R: It is from the verb "vary", you know the meaning...I'm sure

25. S1: different...yes ..it is about different places.....yes this is the answer yes

26. R: ye... good 
The next excerpt demonstrates student S1's application and improvement after the first attempt:

27. R: Now, passage 2, read it and answer question 7.

(After some minutes)

28. S1: there is.... "however"

29. S1: it is number c

30. R: How did you choose it?

31. S1: main idea should be after "however"....

(she starts to read the sentences after "however"

32. S1: During the course of the next twoEnglish began to spread around....

33. S1: I think it is c.

Here, we see that student S1 successfully applying what was shown during the initial intervention, revealing a near transfer of learning. Near transfer "involve(s) the principles learned originally but in different combinations" as opposed to far transfer or very far transfer, which involve more novelty, or maintenance which "involve(s) no transformations" in a given activity (Campione \& Brown, 1990, p. 152). Indicators of transfer are indicators of learning and while "transfer tasks differ in degree of similarity... [they] require the same underlying skills and abilities" (Toglia \& Cermak, 2009, pp.571, in reference to Toglia, 2005).

Hence, it is important to provide mediations and instructional activities that offer the student opportunity to not only understand at a given moment, but to extend student understanding in order to build affordances for independent application. In so doing, the student reveals the beginnings of transfer, and student learning and development are become 'visible' to the researcher. It is important to note, therefore, that the data collected through the structured interviews provided additional information to the researcher with regard to a diagnostic basis upon which to design assistance for mediation sessions.

In another example, the interview with student S4, as well as his pretest, revealed that his difficulty in reading comprehension was quite different from that of student S1:

34. R: What strengths or weaknesses you have in reading comprehension?

35. S4: (After long pause) um...

36. R: What are you good at or.....

37. S4: It is more on meaning of the words......

38. S4.I can't find the main idea....words are very important

As a result, the first intervention session with student S4 was designed to address procedures for tackling unknown word meanings:

39. R: In this passage, are there any words you don't know the meaning?

40. S4: Yes. Many words .......proper....sophisticated....demonstrate....

41. R: Some words you don't know.........what do you do, then?

42. S4: It is very hard I can't understand....I become tired and

43. R: Read the passage now and try to skip the words

(starts reading and saying what he understands )

44. R: ..... guess the meaning, ,....use your knowledge to guess

45. R: read question 6 
46. S4: The word "indiscriminately" ......i don't know it

47. R: First it is important to know its part of speech

48. S4: gheyde (it is an adverb)

49: R. : Read the items ....the answers, do you know them?

50. S4: randomly........angrily.........nosily.......but destructively? I don't know

51. R: Now, look at the sentence .....read it

52. R: is it good to throw your food.......

53. S4: No (laughingly) ...then angrily and noisily.. nemitoneh bashe

(cannot be the answer) then

54. I think it is "randomly"

This initial mediation session was very helpful to student S4; he began to use what he already knew, his own knowledge, to figure out the meaning of unknown words.

55. R: Now, read question 13

(read question 13 in passage 2)

56. the word "proliferated"

57. R: do you know what it means?

58. S4: No, I should say .....it is a verb in the past tense..... yes?

59. R: Yes

60. S4: then, the answers.....prospered ....i don't now ..organized...

61. S4: ....disband ..i don't know....expand...then the sentence ......line ....8

62. R: You have to read the previous sentence too .....you have " these"

63: R: ....a pronoun marja zamir chiye

(what is the antecedent)

64. R: Are there any words you can relate it to the word "proliferated"?

65. S4: dar 2 gharn.....english shor be gostaresh.......

(In 2 centuries English began to spread........)

66. R: one.. word ..in the next sentence might help ...(pointing at the sentence)

67. a word ...........similar to spread.......

68. S4: um....grow? yea I think grow.......(looking at the items in the question)

69. expand?.....javab expand mishe?

(Is the answer expand?)

70. R: Yes, very good

Evidence of near transfer occurs immediately following, during the student's first DA session, as student S4 easily applies the procedure to discover the correct answer in question 27:

71. R: In passage 3, what about the word "dilapidated" ....question 27?

72. S4: sefate ..(reading the answers and the sentence) bayad shabih e ...old bashe

(It is an adjective .......it must be a word similar to "old"

73. I think "d" .......

74. R: Good

In other words, it was through the interaction with student S4 the researcher realized that initially $S 4$ neither attempted to apply his background knowledge to speculate on the meaning of unknown terms, nor did he take advantage of the information available through context. However, based on the researcher's diagnosis 
and the evidence during the mediation session, application of a new process is demonstrated. Transfer, that is learning that had led to development, becomes evident in line 72 as student S4 quickly refers to the word "old" to speculate on the meaning of the new word "dilapidated."

\section{Lens at a Distance: General Procedures and Results}

In the first intervention sessions the students were also given some pages about reading comprehension strategies from Brown (2001) to study for the second mediation session. The second sessions were arranged approximately one week later. In the second session, the students were involved in working through what they had learned about strategies from Brown (2001) and most of the students acknowledge that the mediation sessions were extremely useful. Overall, they were quite satisfied with the dialogic approach used in the intervention sessions. They were also satisfied with the format of the interventions and stated that they found one-on-one format quite motivating as they felt comfortable during the interactions.

After three sessions of the intervention program, the students were given the static posttest. The students' performance improvement is evident by comparing the pretests (Series 1) to posttest (Series 2). The figures 1, 2, and 3 illustrate the change.

Figure 1, on main idea, reveals performance change in the students' ability to find the main idea from pretest to post test. Student S2 reveals dramatic improvement in this sub skill. The dialogic mediations with student S2 uncovered not only the student's difficulties in finding the main idea of a passage, but revealed the way the student's strategies (or lack thereof) for addressing word meaning were impacting understanding of the main idea. S2 initially sought to spot the main idea by relying on the words that most frequently appeared in the text and, as a result, became confused with the details and by unknown words. Not surprisingly, S2 did not try to speculate on the meaning of the words. As a result, the student's improvement in the word meaning sub skill after the mediation with regard to main idea could be predicted.

However, as Poehner (2008, p. 125) notes, it is a mistake to expect that DA miraculously increases learners' abilities. The performance of the students S5 and S6 in the main idea sub skill are the evidence of the Vygotsky's theory of unpredictability vis-à-vis the process of development. During the interactions with the student S5 the researcher realized that the mediation did not prompt the student to consider applying strategies useful and effective in finding an answer.

75. R: What strengths do you have in reading comprehension?

76. R: What weaknesses? Good points or...

77. S5: I don't know ....but I am very weak in reading... when I read I

78. S5: understand but I can't say

77. S5: what I understand and when I see difficult words I can't understand

78. S5: anything....and I ..

79. R: don't you try to skip the words?

80. S5: I can't.

81. R: There are some strategies you can use

At one point during the intervention with the student S5, the researcher realized that the student was resistant to applying the strategies that were being 
taught for while the student gave a correct answer, the student still relied on their own impression from the text (lines 87 and 89).

82. R: Read passage2 and answer question number 7.

(She starts reading, after some minutes)

83. S5: gofte ke bad az chan sal ...600 sal English .......non-native means?

84. S5: the text is about after some years ....600 years...English... what does

85. S5: non-native mean?

86. R: Americans are native speakers but we are non-native speakers.

(She continues reading the passage silently)

87. S5: the answer is " $c$ "

88. R: why do you think it is the main idea? How did you find it?

89. S5: khob gofte aval English ..bad..

(because it is saying that first, English was...)

90. R: Are there any words or clues to help you?

Here we see evidence that the student S5 is unaware of or unwilling to engage strategies that could be applied in other situations. This was substantiated by the poor performance by student S5 on the posttest. Of note: follow-up in terms of the student S5's ability to engage in metacognitive activity could also be a factor not only with regard to engaging in new ways of working with texts, but also in understanding these new ways and how they might be of future benefit.

In sub skill 1, students S5 and S6 did not demonstrate much movement in their performance from pretest to posttest indicating that they may not have been engaged in activities right within their ZPDs. Vygotsky conceived of the ZPD as a means of understanding the child's readiness or intellectual maturity in a specified domain; a metric designed to provide supplementary information about individual students (Campione, et al, 1984, p. 78). Here, the achievement test score can be viewed as providing a quantitative estimate of current status and, according to Campione, et al, (1984) the students' responses can provide important diagnostic information about them. As a result, it could be concluded that the similar performance of those students in the pretests and the posttests uncovers that they were not ready to work on the material independently and that they likely required further mediation. We might hazard to suggest that these students were engaged in activities beyond their readiness and that the researcher was working ahead of the students' ZPDs.

Alternatively, this may be evidence of Skillen's (2008) argument regarding "the construction zone". He contends that the ZPD is just in advance of one's position and it may be that "a novice may not think to generate a variety of possible solutions before embarking on one approach to a task, whereas a more expert student might" (Skillen, 2008).

\section{Conclusion}

The product-oriented achievement tests administered in most EFL educational programs are important as graduation requirements whereas what is really learned as well as how that learning is achieved seems less of a concern. On the other hand, the process-oriented dynamic assessment framework of the present study focuses on fostering students' reading comprehension performance. Here the mediation 
program was aimed at promoting the development of the EFL students' cognition with regard to three reading comprehension sub skills: finding the main idea, inference, and figuring out the meaning of unknown words provided. And while these sub skills are, without a doubt, intrinsically interrelated, the division allowed the researcher to provide more opportunities to assist the students, specifically focusing on certain issues in each mediation session.

The addition of the structured interview also provided important data which revealed that the students found themselves weak in reading comprehension due to their limited vocabulary. They believed that if they knew more words they could have performed much better on the pretest. Thus the data collected through structured interviews provided the researcher with a diagnostic basis upon which to begin to design the assistance for individualized mediation sessions. Returning to the students' replies to the questions during the interviews, we can suppose that the poor performances of students S1, S2 and S7 in their pretests may have been due to a lack of strategies or a repertoire of inadequate strategies with which to fall back on when answering comprehension questions. Future research might address the issue of student modifiability or how much and what type of mediation is needed by a student to take advantage of the process. Quantifying and qualifying hints (Duvall, 2008) or perhaps consideration of the size of the ZPD might be a way to investigate the variation in student receptiveness and transcendence or transfer. That is, consideration of students "who have "larger" and "smaller" zones of proximal development... [where] "size" refers to the extent to which a child can take advantage of collaboration to realize performance beyond what is specified by independent performance" (Chaiklin, 2003). What counts as 'taking advantage' would need to be considered here.

Overall, the results of the study do suggest that static test procedures, which are the typical of most assessment approaches in EFL programs, dramatically underestimate the level of functioning of a learner. Even formative assessment, which has many similarities to DA, does not take into consideration modifiability or the role of transfer. DA, on the other hand, offers a chance for language teachers to more accurately gauge a student's level of understanding and awareness and thereby determine what may be targeted to promote the level of development of the student in relation to their current level of independent and assisted performance. Simply stated, by engaging in DA activity teachers may be able to challenge individuals to reach higher levels of functioning (Poehner, 2005).

Not surprisingly, dynamic assessment even with all its practical limitations has been regarded as partial solution to the disadvantages of traditional tests. The results of this paper suggest that further research on the effects of mediations in dynamic assessment and in strengthening language skills, specifically reading comprehension, are warranted. 


\section{References}

Antón, M. (2009). Dynamic assessment of advanced second language learners. Foreign Language Annals 42(3), 576-598. doi:10.1111/j.1944-9720.2009.01030.x

Baudoin, M. E., et al. (1977). Reader's choice: A reading skills textbook for students of English as a second language. Michigan: The University of Michigan Press.

Baxter, P., \& Jack, S. (2008). Qualitative case study methodology: Study design and implementation for novice researchers, The Qualitative Report, 13(4), 544-559.

Best, J. W. (2006). Research in education (10 th ed.). Boston: Pearson.

Black, P. J. (1993). Formative and summative assessment by teachers. Studies in Science Education, 21(1), 49-97. doi:10.1080/03057269308560014

Black, P., \& Wiliam, D. (1998). Assessment and classroom learning. Assessment in Education: Principles, Policy, and Practice, 5(1), 7-74.

Broadfoot, P. M. (2005). Dark alleys and blind bends: Testing the language of learning. Language Testing, 22(2), 123-141. doi 10.1191/02655322051t302oa

Brown, H. D. (2001). Teaching by principles: An integrative approach to language pedagogy. London: Longman.

Brown, A. L., \& Ferrara, R. A. (1985). Diagnosing zones of proximal development. In J. V. Wertsch (Ed.), Culture, communication, and cognition: Vygotskian perspectives (pp. 273-305). New York: CUP.

Campione, J. C. (1989). Assisted assessment: A taxonomy of approaches and an outline of strengths and weaknesses. Journal of Learning Disabilities, 22(3), 151165.

Campione, J. C., \& Brown, A. L. (1990). Guided learning and transfer: Implications for approaches to assessment. In N. Frederiksen, R. Glaser, A. Lesgold, \& M. G. Shafto (Eds.), Diagnostic monitoring of skill and knowledge acquisition (pp. 141172). Hillsdale: New Jersey.

Campione, J. C., Brown, A. L., Ferrera, R. A., \& N. R. Bryant. (1984). The zone of proximal development: Implications for individual differences and learning. In B. Rogoff, \& J. V. Wertsch (Eds.), Children's Learning in the Zone of Proximal Development (pp. 77-92). San Francisco, CA: Jossy-Bass.

Chaiklin, S. (2003). The zone of proximal development in Vygotsky's analysis of learning and instruction. In A. Kozulin, B. Gindis, V. Ageyev, \& S. Miller (Eds.), Vygotsky's educational theory and practice in cultural context. Cambridge: CUP.

Crick, R. D., \& Yu, G. (2008). Assessing learning dispositions: Is the Effective lifelong learning inventory valid and reliable as a measurement tool? Educational Research, 50(4), 387-402. doi: 10.1080/00131880802499886

Crooks, T. J. (1988). The impact of classroom evaluation practices on students. Review of Educational Research, 58(4), 438-481. doi: 10.3102/00346543058004438

Dornyei, Z. (2007). Research methods in applied linguistics. Oxford: OUP.

Duvall, E. (2007). What a difference an ideology makes: An alternative pedagogical orientation to neoliberal values in education. In R. Alanen, \& S. Pöyhönen (Eds.), Language in actions: Vygotsky and Leontievian legacy today (pp. 124-159). Newcastle: Cambridge Scholars Publishing.

Duvall, E. (2008). No secrets to conceal: Dynamic assessment and a state mandated, standardized $3 r d$ grade reading test for children with learning disabilities. 
(Unpublished doctoral dissertation). The Pennsylvania State University, the U.S.

Dysthe, O., \& Engelsen, K. S. (2011). Portfolio practices in higher education in Norway in an international perspective: Macro-, meso- and micro-level influences. Assessment \& Evaluation in Higher Education, 36(1), 63-79. doi: $10.1080 / 02602930903197891$

Freire, P. (1970). Pedagogy of the oppressed. New York: Continuum.

Feuerstein, R., \& Feuerstein R. S. (2001). Is dynamic assessment compatible with the psychometric model? In A. S. Kaufman, \& N. L. Kaufman (Eds.), Specific learning disabilities and difficulties in children and adolescents: Psychological assessment and evaluation (pp. 218-246). New York: CUP.

Gipps, C. (1994). Beyond testing: Towards a theory of educational assessment. London: Falmer Press.

Gipps, C. (1999). Socio-cultural aspects of assessment. Review of Research in Education, 24, 355-392. doi: 10.3102/0091732X024001355

Grab, W. (2009). Reading in a second language. Cambridge: CUP.

Grifin, P. (2009). Teacher's use of assessment data. In C. Wyatt-Smith, \& J. Cumming (Eds.), Educational assessment in the 21 ${ }^{\text {st }}$ century (pp. 183-209). Pennsylvania: Springer.

Grigorenko, E. L., \& Sternberg, R. G. (1998). Dynamic testing. Psychological Bulletin, 124(1), 75-111. Doi: 10.1037/0033-2909.124.1.75

Grigorenko, E. L. \& Sternberg, R. G. (2002). Dynamic testing: The nature and measurement of learning potential. New York: Cambridge University.

Gutierrez, V. F. (2000). Dynamic assessment: An approach to assessing children's language learning potential. Seminars in Speech and Language, 21(3), 214-223.

Haywood, H. C., \& Lidz, C. S (2007). Dynamic assessment in practice: Clinical and educational applications. Cambridge: CUP.

International Center for the Enhancement of Learning Potential. (2011). Basic Theory. Retrieved from: http://www.icelp.org/asp/Basic_Theory.shtm

Jönsson, A., Mattheos, N., Svingby, G., \& Attström, R. (2007). Dynamic assessment and the"Interactive Examination". Educational Technology \& Society, 10(4), 1727.

Kirkland, M. C. (1971). The effects of tests on students and schools. Review of Educational Research, 41(4), 303-350. doi: 10.3102/00346543041004303

Kozulin, A., \& Pressisen, B. Z. (1995). Mediated learning experience and psychological tools: Vygotsky's and Feuerstein's perspectives in a study of student learning. Educational Psychologist, 30(2), 67-75. doi:10.1207/s15326985ep3002_3

Kozulin, A. (2005). Learning potential assessment: Where is the paradigm shift? In D. B. Pillemer, \& S. H. White (Eds.), Developmental psychology and social change: research, history, and policy (pp.352-366). New York: Cambridge University Press.

Kozulin, A., \& Garb, E. (2001). Dynamic assessment of EFL text comprehension of at risk students. Paper presented at the $9^{\text {th }}$ conference of the European association for Research on Learning and Instruction, Fribourg, Switzerland. Retrieved from www.icelp.org/files/research/DynamicAssessOfEFL.pdf 
Lantolf, J. P. \& Poehner, M. (2008). Dynamic assessment. In E. Shohamy, \& N. H. Hornberger (Eds.), Encyclopedia of language and education (pp. 273-284). London: Springer Science.

Lantolf, J. P., \& Thorne, S. L. (2006). Sociocultural theory and the genesis of L2 development. Oxford: Oxford University Press.

Lidz, C. S. (1983). Dynamic assessment and the preschool children. Journal of Psychoeducational Assessment, 1(1), 59-74. doi: 10.1177/074193258901000210

Missiuna, C. \& Samuels, M. (1988). Dynamic assessment: Review and critique. Special Services in the Schools, 5(1). doi: 10.1300/J008v05n01_01

Nassaji, H., \& Cumming, A. (2000). What's in a ZPD? A case study of a young ESL student and teacher interacting through dialogue journals. Language Teaching Research, 4(2), 95-21. doi: 10.1177/136216880000400202

Philips, D. (1996). Longman preparation course for the TOEFL test. London: Longman

Poehner, M. (2005). Dynamic assessment of oral proficiency among advanced L2 learners of French. (Unpublished doctoral dissertation). The Pennsylvania State University, the U.S.

Poehner, M. (2007). Beyond the Test: L2 Dynamic assessment and the transcendence of mediated learning. Modern Language Journal, 91(3), 323-340. doi: 10.1111/j.1540-4781.2007.00583.x

Poehner, M. (2008). Dynamic assessment: A Vygotskian approach to understanding and promoting L2 development. Pennsylvania: Springer.

Poehner, M., \& Lantolf, J. P. (2005). Dynamic assessment in the language classroom. Language Teaching Research, 9(3), 233-265. doi: 10.1191/1362168805lr166oa

Shepard, L. A. (2000). The role of classroom assessment in teaching and learning. Los Angeles: University of California.

Skillen, P. (2008). The construction zone. Retrieved from http://www.peterskillen.org/Peters_Home/School_Stuff_files/The\%20Cons truction \%20Zone \% 20-\%20Open\%20to\%20All.pdf.

Thouësny, S. (2010). Assessing second language learners' written texts: An interventionist and interactionist approach to dynamic assessment. Proceedings of World Conference on Educational Multimedia, Hypermedia and Telecommunications (EDMEDIA), Toronto, Canada.

Toglia, J., \& Cermak, S. A. (2009). Dynamic assessment and prediction of learning potential in clients with unilateral neglect. American Journal of Occupational Therapy, 64, 569-579. doi: 10.5014/ajot.63.5.569

Wells, G. (2000). Dialogic inquiry in education: Building on the legacy of Vygotsky in C.D. Lee and P. Smagorinsky (Eds.), Vygotskian perspectives on literacy research (pp. 51- 85). Cambridge: CUP.

Wertsch, J. V. (1979). From social interaction to higher psychological processes: a clarification and application of Vygotsky's theory. Human Development, 22(1), $1-22$.

Wertsch, J. V. (1985). Introduction. In J. V. Wertsch (Ed.), Culture, communication, and cognition: Vygotskian perspectives (pp. 1-18). New York: Cambridge University Press.

Wyatt-Smith, C. (2006). Assessment for learning: An Australian study in middle schooling. Presented at the $32^{\text {nd }}$ Annual Conference, International Association for 
Educational Assessment. Retrieved from

http:/ / www.iaea.info/documents/paper_1162a16f3c.pdf

Wyatt-Smith, C., Gunn, S. (2009). Towards theorizing assessment as critical inquiry.

In C. Wyatt-Smith, \& J. Cumming (Eds.), Educational assessment in the 21sth

century (pp. 83-105). London: Springer.

Vygotsky, L. (1978). Mind in society: The development of higher psychological processes.

Cambridge: Harvard University Press.

\section{Appendix}

Table 1

Dynamic Assessment and Non-dynamic Assessment Comparison

\begin{tabular}{|c|c|}
\hline Dynamic Assessment & Non Dynamic Assessment \\
\hline $\begin{array}{l}\text { - It is processed-oriented. } \\
\text { - The learners' developmental } \\
\text { changes are tracked and supported. } \\
\text { - Learners become more responsible } \\
\text { on their own learning. } \\
\text { - The examiner takes active role } \\
\text { during the testing situation. (Anton, } \\
\text { 2009). } \\
\text { - The teacher acts as facilitator of } \\
\text { language-processing and problem- } \\
\text { solving techniques. } \\
\text { - The student learns to become an } \\
\text { active user of self-monitoring } \\
\text { strategies to regulate their own } \\
\text { understanding. } \\
\text { The goal is to enhance students' } \\
\text { conceptual understandings and to } \\
\text { produce more insightful intentional } \\
\text { learners. (Campione, 1989) }\end{array}$ & $\begin{array}{l}\text { - It is product-oriented. } \\
\text { - } \quad \text { Tearners are not supported. } \\
\text { evaluate specific instructional } \\
\text { strategies for remediating learning } \\
\text { deficits. } \\
\text { - The examiner is neutral. } \\
\text { - Opportunity to directly influence } \\
\text { learning is overlooked within the } \\
\text { context of traditional assessment. } \\
\text { - Traditional assessment does not } \\
\text { recognize the learner's potential to } \\
\text { succeed with adequate } \\
\text { environmental support. } \\
\text { The assumption underlying these } \\
\text { tests are: All the students have had } \\
\text { the same opportunities to acquire } \\
\text { the information and skills probed in } \\
\text { the tests (Campione, 1989) }\end{array}$ \\
\hline
\end{tabular}

Table 2

Results of the Pretest and Posttest: Correct Answers to the Questions

\begin{tabular}{|c|c|c|c|c|c|c|c|c|}
\hline \multirow{3}{*}{$\begin{array}{l}\text { Student } \\
\text { Number }\end{array}$} & \multicolumn{2}{|c|}{ Sub Skill 1} & \multicolumn{2}{|c|}{ Sub Skill 2} & \multicolumn{2}{|c|}{ Sub Skill 3} & \multicolumn{2}{|c|}{ Sub Skill 4} \\
\hline & \multicolumn{2}{|c|}{ Main Idea (4) } & \multicolumn{2}{|c|}{ Inference (6) } & \multicolumn{2}{|c|}{ Word Meaning } & \multicolumn{2}{|c|}{ Detail (6) } \\
\hline & Pre & Post & Pre & Post & & Post & Pre & Post \\
\hline 1 & 2 & 4 & 2 & 6 & 3 & 8 & 1 & 6 \\
\hline 2 & 0 & 2 & 3 & 5 & 4 & 7 & 0 & 4 \\
\hline 3 & 3 & 4 & 6 & 6 & 9 & 10 & 2 & 6 \\
\hline 4 & 2 & 3 & 2 & 2 & 4 & 8 & 1 & 4 \\
\hline
\end{tabular}




\begin{tabular}{|c|ll|ll|ll|ll|}
\hline $\mathbf{5}$ & 3 & 3 & 5 & 5 & 8 & 9 & 2 & 6 \\
\hline $\mathbf{6}$ & 3 & 3 & 4 & 5 & 3 & 9 & 2 & 7 \\
\hline $\mathbf{7}$ & 2 & 3 & 1 & 4 & 4 & 7 & 2 & 4 \\
\hline $\mathbf{8}$ & 2 & 3 & 3 & 5 & 5 & 8 & 1 & 5 \\
\hline $\mathbf{9}$ & 1 & 2 & 2 & 5 & 4 & 8 & 1 & 5 \\
\hline $\mathbf{1 0}$ & 3 & 2 & 2 & 4 & 3 & 8 & 1 & 5 \\
\hline
\end{tabular}

Figure 1. Main Idea Performance Change for the Students S1-S10

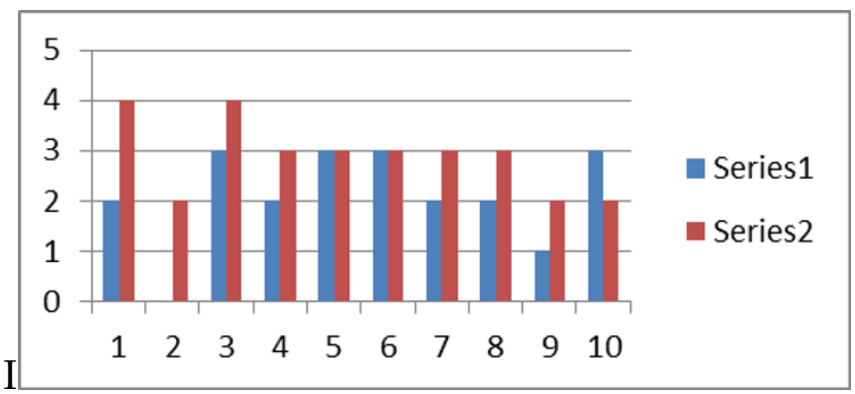

It reveals the change in the performance of the students' ability to find the main idea from pretest to post test.

Figure 2. Inference performance change for students S1-S10

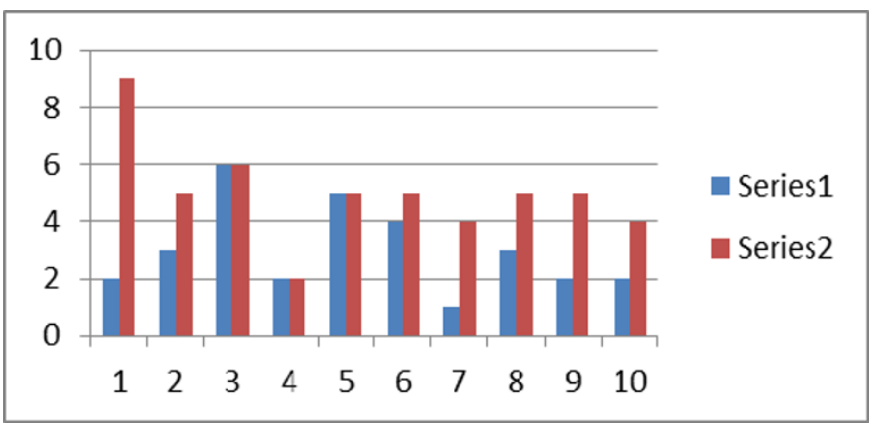

Figure 3. Word meaning performance change S1-S10

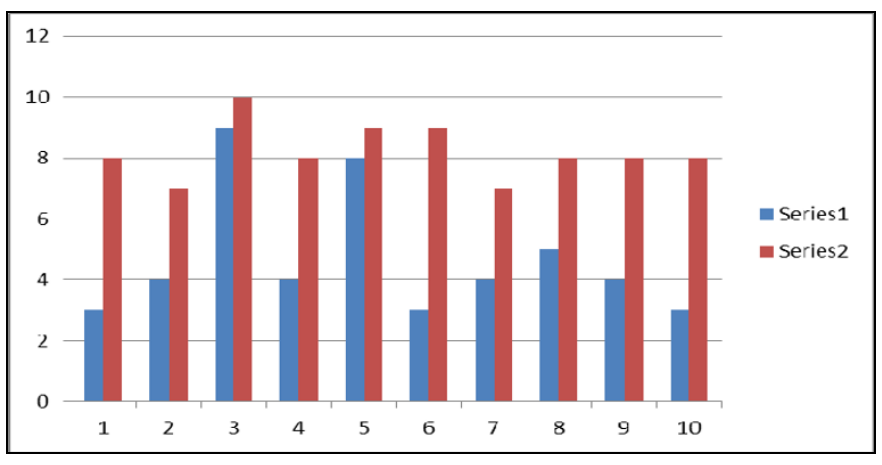

